\title{
HUKUMAN BAgI PEZINA Di SARAWAK MALAYSIA
}

\author{
Ahmad Syazman Bin Othman \\ syazmanbo@gmail.com \\ No. 29 Kampung Hilir Sibu Sarawak \\ Malaysia
}

\begin{abstract}
The legal settlement for adulterer in Sarawak Malaysia, the Shari'ah Court in Sarawak Malaysia bases its decition on the provisions of Ordinan 46 Year 2001 on an error ordinan of the criminal Islamic law 2001 relating to morality of the Judge of the Shari'ah High Court in Sarawak Malaysia. Adulterer is sentenced by penalty for not more than five thousand Ringgits or imprisonment for not more than three years. In relation with the implementation of the sanction for offender who has committed the crime of adultery, it needs to be given authority for provincial parliament and DUN which represents the province in order to be together in setting laws and it should not ignore sharîah. This is the importance of uniting between Muslim scholar ('ulama) and Muslim intellectual in acquainting to the public about the Islamic law. Shari'ah Court or the institution that runs the Islamic law should have full authority in carrying out the law and rexisting to spread and explain the real meaning of the Islamic law to be enacted.

Keywords: Criminal penalty, adulterer, Sarawak.
\end{abstract}

Abstrak: Dalam penyelesaian perkara bagi pezina di Sarawak Malaysia, Mahkamah Syariah di Sarawak Malaysia berdasarkan pada ketentuan Ordinan 46 Tahun 2001 Ordinan Kesalahan Jinayah Syariah 2001 yang berhubungan dengan kesusilaan oleh Hakim Mahkamah Tinggi Syariah di Sarawak Malaysia dijatuhi pidana denda tidak melebihi lima ribu ringgit atau penjara selama tempo tidak melebihi tiga tahun atau disebat tidak melebihi enam sebatan atau dihukum dengan mana-mana kombinasi hukuman itu. Dalam hal pelaksanaan sanksi bagi pelanggar yang telah melakukan tindak pidana perzinaan, perlu diberikan kewenangan kepada Parlimen bagi propinsi maupun DUN yang mewakili propinsi agar dapat bersama dalam menetapkan undang-undang, dan seharusnya tidak mengenepikan Syariat. Pentingnya ada pemersatuan ulama dan para cendekiawan dalam mengenalkan masyarakat tentang hukum Islam yang sebenarnya. Mahkamah Syariah maupun lembaga yang menjalankan hukum Islam haruslah mempunyai wewenang yang penuh dalam menjalankan hukum agama dan mendukung kerajaan dengan menyebar dan menerangkan arti sebenar hukum Islam yang ingin diberlakukan.

Kata Kunci: Hukuman, pezina, Sarawak 


\section{Pendahuluan}

Manusia ditunjuk oleh Allah sebagai khalifah di bumi ini diberikan akal, untuk dipergunakan dalam merealisasikan keinginannya, yaitu berupa daya dan karsanya sehingga mampu mendeteksi mana yang baik dan mana yang buruk untuk dilakukan. Jadi akal merupakan anugerah yang paling istimewa sekaligus pembeda antara manusia dengan makhluk ciptaan-Nya yang lain.

Dengan demikian, akal yang sehat dan jujur tidak akan melupakan realitas dan asal-usulnya yang tertanam di dalam prinsipprinsip samawi dan terkristal di dalam syari'at Islam yang suci. Akal tidak akan menyimpang dari kebenaran, manakala kebenaran tampak di hadapannya dan akal menjalani aktifitas ilmiahnya tanpa dipengaruhi oleh hawa nafsu dan keinginan-keinginan tertentu.

Akan tetapi bila akal seseorang telah terpengaruh dan dikuasai oleh hawa nafsu, maka terjadilah penyimpangan terhadap perilaku manusia, sehingga timbul keinginan untuk melakukan pelanggaran atau kejahatan. Hal ini telah dijelaskan dalam firman Allah:

"Dan aku tidak membebaskan diriku (dari kesalahan), karena sesungguhnya nafsu itu selalu menyuruh kepada kejahatan, kecuali nafsu yang diberi rahmat oleh Tuhanku. Sesungguhnya Tuhanku Maha Pengampun lagi Maha Penyayang." (Q.S. Yusuf: $53)^{1}$

Dengan akal semata, manusia tidak akan sanggup mengatur bumi beserta isinya tanpa ada sesuatu yang dijadikan pedoman atau landasan dalam hidupnya. Untuk memenuhi kebutuhan manusia, Allah swt menurunkan al-Qur'an yang di dalamnya terdapat petunjuk yang dijadikan pedoman tentang tata cara hidup dan berkehidupan yang baik, agar tercapai kebahagiaan material dan spiritual sehingga tidak terlena dengan kehidupan dunia.

Al-Qur'an yang berfungsi sebagai pedoman hidup manusia tidak hanya dapat dijadikan pedoman dalam mengarungi kehidupan dunia saja, namun lebih dari itu, al-Qur'an merupakan petunjuk untuk dapat mencapai kebahagiaan di akhirat.

Begitu pula dalam masalah seksual (persetubuhan), Allah swt telah menetapkan tata cara melakukannya dengan baik dan benar pada

\footnotetext{
1 Yayasan Penyelenggara Penterjemah/Pentafsir al-Qur'an, Al-Qur'ân al-Karîm wa Tarjamah Ma'ânîhi Ila Al-Lughah al-Indûnîsiyyah, 357.
} 
tempatnya, yaitu kepada seorang suami/isteri yang sah atau disebut dengan pernikahan. Hal ini dijelaskan dalam firman-Nya:

"Dan di antara tanda-tanda kekuasaan-Nya ialah Dia menciptakan untukmu isteri-isteri dari jenismu sendiri, supaya kamu cenderung dan merasa tenteram kepadanya, dan dijadikanNya diantaramu rasa kasih dan sayang. Sesungguhnya pada yang demikian itu benar-benar terdapat tanda-tanda bagi kaum yang berfikir." (Q.S. Ar-Rûm:21)

Maka dari itu Allah melarang hambaNya melakukan seks bebas atau perzinaan, karena yang demikian termasuk perbuatan keji dan termasuk dosa besar. Larangan ini ditegaskan Allah dalam firman-Nya:

"Dan janganlah kamu mendekati zina; sesungguhnya zina itu adalah suatu perbuatan yang keji dan suatu jalan yang buruk." (Q.S. Al-Isra':32) ${ }^{2}$

Dengan memahami ayat-ayat dan hadis Rasulullah di atas, diketahui bahwa zina adalah suatu perbuatan yang dilarang oleh Allah dan merupakan dosa besar.

Malaysia mempunyai penduduk yang mayoritas beragama Islam, akan tetapi hukum Islam belum secara keseluruhan diberlakukan bagi ummatnya. Sedangkan hukum di Malaysia dilihat dari segi penerapannya belum maksimal serta sanksi-sanksi terhadap tindak pidana terlalu ringan, hal ini yang membuat masyarakat banyak melakukan tindak kejahatan serta berbuat asusila tanpa malu-malu.

Di Malaysia, ketika masih menjadi Tanah Melayu pada zaman lampau yaitu sebelum berlaku penjajahan, mengamalkan undang-undang Islam dan menganut Mazhab Syafi'i. Bukti kewujudan peruntukan mengenai hukuman zina ini seperti yang terpahat pada Batu Bersurat Terengganu yang bertanggal 22 Februari 1303 berkenaan dengan hukuman terhadap pesalah-pesalah zina. ${ }^{3}$

Perundangan Islam dipercaya mulai diamalkan oleh golongan masyarakat Islam sejak perkembangan pemerintahan kerajaan Melayu Melaka, keadaannya semakin jelas apabila raja pada masa itu telah memeluk Islam. Pada peringkat awal pelaksanaan, hanya pada soal

\footnotetext{
${ }^{2}$ Ibid., 429.

${ }^{3}$ Difahami dari petikan tersebut: "Orang berbuat bala cara laki-laki perempuan satitah Dewata Maha Raya jika merdeka bujang palu seratus rotan. Jika merdeka beristeri atau perempuan ditanam hinggakan pinggang dihambalang dengan batu matikan."
} 
ibadah dan nikah kawin. Setelah itu agak menyeluruh pada beberapa bahagian undang-undang sipil dan jinayah. ${ }^{4}$

Pengumpulan hukum kanun Melaka ini diyakini berawal pada zaman Sultan Muhammad Shah (1424-1444M) dan disempurnakan pada zaman pemerintahan Muzaffar Shah. Hukum kanun Melaka ini dibagikan peruntukannya kepada dua bagian yaitu hukum adat dan hukum shara', terdapat empat peruntukan yang menyentuh hukum shara' dalam hukum kanun Melaka. ${ }^{5}$

1. Undang-undang Perkawinan Islam

2. Undang-undang Muamalah Islam

3. Undang-undang keterangan Islam

4. Undang-undang Jinayah Islam

Melihat pada hukum atau aturan ini adalah sebagai himpunan peraturan-peraturan (perintah dan larangan) yang mengurus tata tertib suatu masyarakat oleh karena itu harus ditaati oleh masyarakat.

Begitu pun, situasi ini mulai berubah dengan kedatangan penjajah Inggris. Sekalipun undang-undang Islam ialah undang-undang asas dan undang-undang negeri Semenanjung Malaysia, tetapi pengaruh orangorang Inggris telah membuat undang-undang Inggris berkuasa di Semenanjung Malaysia. ${ }^{6}$

Mengenai hukuman pelaku pezina, syariah inilah yang sering menimbulkan polemik dalam masyarakat di Malaysia. Polemik ini terjadi karena ketidakfahaman tentang pelaksanaan undang-undang berkaitan hukuman bagi pelaku pezina yang dilaksanakan mengikut undangundang syariah, malah seringkali disamakan dengan undang-undang jinayah sipil, baik dari segi konsep dan pelaksanaan walau pun pada hakikatnya ia adalah sesuatu yang berbeda.

Berdasarkan hal tersebut, maka artikel ini akan membahas tentang hukuman bagi pelaku tindak pidana perzinaan di Sarawak Malaysia.

\footnotetext{
${ }^{4}$ Abd Monir Haji Ya'kub, Perkembangan Perundangan Islam (t.tp: Penerbitan Sarjana (M) sdn bhd, 1985), 66.

${ }^{5}$ Zaini Nasohah, Pentadbiran Undang-undang Islam di Malaysia Sebelum dan Menjelang Merdeka, 4.

6 Mahyudin Haji Yahya, Islam dan Pembangunan Negara (Malaysia: Penerbit University Kebangsaan Malaysia, 1986), 12.
} 


\section{Konstruksi Hukum Perzinaan dalam Islam}

Hukuman untuk orang yang melanggar aturan shara' dikatakan ḥudûd, kata hudûd adalah bentuk jama' dari kata had yang berarti pemisah antara dua hal atau yang membedakan antara sesuatu dengan yang lain. Secara bahasa, had berarti pencegahan, maka hukuman yang dijatuhkan kepada pelaku kemaksiatan disebut hudûd, karena hukuman tersebut dimaksudkan untuk mencegah agar orang yang dikenakan hukuman itu tidak mengulangi perbuatan yang menyebabkan dia dihukum, had menurut istilah shara' pula adalah pemberian hukuman dalam rangka hak Allah.

Hudûd adalah hukum Allah, tidak berdiri sendiri malah berada dalam satu sistem Islam yang komprehensif, saling lengkap melengkapi antara satu komponen dengan satu komponen yang lain. Hudûd merupakan salah satu komponen dari Islam, kaedah pelaksanaan dan tujuan pencegahnya dibuat "Karena Allah" dan bukan dengan tujuantujuan yang lain.

Berdasarkan ayat al-Qur'an yang membahas tentang zina, dapat dipahami hukum sebagai berikut:

1. Perempuan yang berzina dan laki-laki yang berzina hukuman dari tiap-tiap orang dari keduanya seratus kali cambuk.

2. Pelaksanaan hukuman cambuk bagi pezina pada poin $1 \mathrm{di}$ atas, tidak boleh ada belas kasihan kepada keduanya yang mencegah kamu untuk menjalankan hukum Allah jika kamu beriman kepada Allah dan hari akhirat.

3. Pelaksanaan hukuman kepada pezina harus disaksikan oleh sekumpulan orang-orang yang beriman.

4. Para wanita yang mengerjakan perbuatan keji dalam bentuk zina harus disaksikan oleh 4 orang saksi.

5. Apabila 4 orang dimaksud, memberi persaksian kepada wanitawanita yang melakukan zina, maka wanita-wanita itu harus dikurung dalam rumah sampai meninggal atau sampai Allah memberi jalan yang lain kepadanya.

6. Janganlah kamu mendekati zina karena zina itu adalah suatu perbuatan yang keji dan suatu pekerjaan yang buruk.

7. Wanita yang beriman harus menahan pandangannya dan memelihara kemaluannya. 
8. Wanita yang beriman tidak boleh menampakkan perhiasannya, kecuali yang biasa tampak daripadanya.

9. Wanita yang beriman harus menutup kain kudung dadanya, dan tidak menampakkan perhiasannya, kecuali kepada suami mereka, atau ayah mereka, atau ayah suami mereka, atau saudara-saudara laki-laki mereka, atau putra-putra saudara laki-laki mereka, atau putri-putri saudara perempuan mereka, atau wanita-wanita Islam, atau budak-budak yang mereka miliki, atau pelayan-pelayan lakilaki yang tidak mempunyai keinginan (terhadap wanita) atau anakanak yang belum mengerti tantang aurat wanita.

10. Wanita yang beriman tidak boleh menggoyangkan kakinya yang mengakibatkan dapat diketahui perhiasaan yang mereka sembunyikan.

11. Wanita yang beriman hendaklah bertaubat kepada Allah supaya dapat beruntung.

Hukuman dalam ḥudûd terbagi tiga macam, yaitu hukuman mati, hukuman potong tangan, dan cambuk, disertai dengan penyaliban atau pengasingan: ${ }^{7}$

a. Hukuman mati diberlakukan dalam empat macam tindak kriminal yaitu;
1) Murtad,
2) Zina muhsan,
3) Meninggalkan shalat karena malas,
4) Dan membegal (merampok).

b. Hukuman potong tangan diberlakukan dalam dua tindak kriminal yaitu;

1) Pencurian

2) Dan membegal (merampok) disertai perampasan harta benda.

c. Hukuman cambuk diberlakukan dalam tiga tindak kriminal. Yaitu;

1) Konsumsi minuman memabukkan,

2) Menuduh berzina,

3) Dan zina selain muhsan.

\footnotetext{
${ }^{7}$ Wahbah Zuhaili, Fikih Imam Syafi'i (Malaysia: Terbitan Al-Mahira, 2010), 259.
} 


\section{Penerapan Kanun Jinayah Syariah di Sarawak Malaysia}

Perundangan Islam dipercaya mulai diamalkan oleh golongan masyarakat Islam sejak terbentuknya pemerintahan kerajaan melayu Melaka, keadaannya semakin jelas apabila Raja pada masa itu telah memeluk Islam. Pada peringkat awalnya pelaksanaan hanya pada soal ibadah dan perkawinan. Setelah itu agak menyeluruh pula pada beberapa bagian undang-undang sipil dan jinayah. ${ }^{8}$

Terdapat beberapa teks undang-undang Melayu lama yang menggambarkan bentuk perundangan yang dipakai pada masa itu yaitu, Hukum Kanun Melaka, Hukum Kanun Pahang, Undang-Undang Kedah dan Perak. ${ }^{9}$

Di Melaka, undang-undang yang dilaksanakan adalah undangundang Islam yang telah dipakai dan sesuaikan dengan adat Melayu. Teks yang dapat dikesan dan dipakai oleh pemerintahan melayu Melaka pada zaman itu ada dua Teks:

1. Undang-Undang Melaka atau Risalah Hukum Kanun ${ }^{10}$, risalah hukum qanun ini telah menjadi kompilasi undang-undang Islam yang menjadi rujukan dan panduan bagi negeri-negeri lain.

2. Undang-undang Laut Melaka, mengandung perkara-perkara yang berhubung dengan peraturan pelayaran dan perniagaan, kesalahan jinayah perdagangan serta bidang kuasa nakhoda (kapten) kapal.

Penulis memberikan contoh bagi Hukum Kanun Melaka, karena Hukum Kanun Melaka ini banyak dijadikan rujukan oleh negeri-negeri lain. Teks Hukum Kanun Melaka ini tidak memuatkan keseluruhan Undang-undang Islam, bahkan bercampur dengan undang-undang adat, tetapi bagian perundangan Islam yang diperuntukkan di dalam teks ini berhubungan dengan perkawinan, perceraian, jual beli, qișâs, dan ḥudûd (jinayah).

Undang-undang Melaka mengenakan hukuman Allah bagi orang yang membunuh, orang yang mencuri, qazaf, dan mengenakan hukum diyat dan ta'zîr.

\footnotetext{
${ }^{8}$ Abd Monir Haji Ya'kub, Perkembangan Perundangan Islam (Malaysia: Penerbitan Sarjana (M) Sdn Bhd, 1985), 66.

9 Zaini Nasohah, Pentadbiran Undang-Undang Islam di Malaysia Sebelum dan Menjelang Merdeka (Malaysia: Percetakan Cergas (M) Sdn Bhd, 2004), 3.

${ }^{10}$ Abdullah Ishak, Islam di Nusantara, Khususnya di Tanah Melayu (Malaysia: Hal Ehwal Islam Jabatan Perdana Menteri, 1992), 147.
} 
Di sini apa yang ingin penulis kemukakan mengenai hukuman terhadap jinayah zina dan meminum yang memabukkan: ${ }^{11}$

Pada pasal dalam kanun Melaka yaitu:

40.1 Pada hukum zina itu atas dua perkara:

Satu : muhsan namanya laki-laki atau perempuan yang sudah bersuami dan nikah yang sah.

Kedua: tiada muhsan, laki-laki yang tiada beristeri dan perempuan yang belum bersuami.

Yang muhsan dihukum rajam dan dilontar dengan batu hingga mati. Maka ghair muhsan hadnya didera seratus kali dan diasingkan ke luar negeri setahun.

Syarat muhsan itu 4 perkara: ${ }^{12}$

a. Islam

b. Baligh

c. Berakal

d. Tiada ia gila (tidak gila)

Adapun hamba laki-laki dan hamba perempuan hadnya setengah daripada merdeka 50 kali palu.

40.2 bermula hukum liwât dan menyertai binatang seperti hukum zina juga. Jikalau tiada setubuh hingga peluk cium juga, dita'zîrkan oleh hakim jikalau dihadkan 20 palunya.

Bermula dihukumkan (oleh hakim zina dengan ikrar atau 4 orang saksi) laki-laki yang merdeka melihat orang zina itu.

Bermula jika 2 orang saksi berkata: "kami melihat ia zina pada suatu penjuru" ; 2 orang berkata-kata: "kami melihat ia zina pada penjuru lain," maka tiada sabit, pada hukum zina itu hendak sekata keempat saksi itu, maka sabit hukum zina, maka dihukumkan seperti adat dahulu jika adanya.

41 pasal yang keempat puluh esa pada menyatakan hukum Islam minum arak dan tuak, maka barang siapa minum arak dan tuak atau minum barang minuman yang memabukkan, jikalau merdeka 40 kali dera akan dia, jikalau abdi 20 kali deranya.

Bermula dihadkan 2 perkara, suatu dengan ikrar, suatu dengan 2 orang saksi laki-laki. Tidak dihadkan dengan dicium bau tuak yakni tiada dihukum padanya. ${ }^{13}$

${ }^{11}$ Ibid., 44.

${ }^{12} \mathrm{lbid}$.

${ }^{13}$ Ibid., 45. 
Berdasarkan hal di atas diketahui bahwa undang-undang Islam ketika itu sudah diterapkan dan dijalankan sesuai dengan hukum Islam.

Menurut ketua hakim Mahkamah Syariah di Sarawak Malaysia:

"Meskipun hukum Pidana Islam di Malaysia menghukum perbuatan zina yang terjadi di kalangan mereka yang sudah menikah, namun hukuman itu bukan karena hubungan seks luar nikah itu sendiri tetapi karena kesalahan 'pengkhianatan rumah tangga'. Berbeda dengan pandangan syariat Islam, ia tidak mengharuskan hubungan seks antara pria dan wanita kecuali berdasakan pernikahan yang sah. Kalau hubungan seperti itu terjadi di luar pernikahan, ia dilihat sebagai perzinaan yang harus dihukum, bukan satu persoalan dalam syariat Islam apakah pesetubuhan haram itu terjadi dengan kerelaan hati kedua belah pihak atau tidak dan apakah melibatkan suami atau isteri orang maupun tidak, namun dalam kasus hukumannya jalan ringan dari mereka yang sudah menikah".

\section{Ketentuan Qanun di Mahkamah Syariah Sarawak Malaysia}

Penerapan hukuman Islam yang berjalan di tanah Melayu yaitu Hukum kanun Melaka yang diberlakukan pada masa Melayu kuno menunjukkan bahwa hukum shara' telah diakui dan dijalankan di tanah Melayu. Sebelum datangnya penjajah, undang-undang yang diikuti di negeri-negeri Melayu ialah undang-undang Islam yang menyerap adat Melayu yang sesuai. Setelah penjajahan Inggris, undang-undang Inggris diterima di negeri-negeri Melayu dengan dua kaedah; Pertama dengan kaedah perundangan melalui perundangan dan Kedua Pihak berkuasa British telah menasehati Raja-raja Melayu agar membuat beberapa undang-undang tertulis dan undang-undang itu semua mengikuti contoh undang-undang Inggris secara langsung atau tidak. ${ }^{14}$

Dalam berbagai perjanjian yang dibuat Raja Melayu dengan pihak Inggris, telah dinyatakan bahawa Raja-Raja Melayu bersepakat menerima semua nasehat Inggris kecuali dalam hal ihwal agama Islam dan adat istiadat Melayu. Walaupun peruntukan tersebut diadakan, namun Inggris pada hakikatnya telah campur tangan dalam hal ihwal Islam serta pentadbirannya. Inggris juga telah memasukkan keputusan hakim ke negeri-negeri selat, negeri-negeri Melayu dan negeri-negeri Borneo dan akhirnya akta undang-undang bertulis yang berkenaan mahkamah

\footnotetext{
${ }^{14}$ Ahmad Mohammed Ibrahim, 41.
} 
hendaklah memakai common law England dan kaedah-kaedah ekuiti yang di England.

Undang-undang Inggris diperkenalkan secara resmi pada tahun 1937. Ketika kedudukan undang-undang Inggris bertambah kukuh, kedudukan undang-undang Islam pula semakin tergoyah dan terpisah karena mahkamah-mahkamah di Malaysia (tidak termasuk syariah) akan menjalankan undang-undang Inggris (common law and equity). ${ }^{15}$ Sekalipun Mahkamah Syariah tidak termasuk dalam menjalankan undang-undang Inggris, tetapi Mahkamah Syariah telah diperuntukan dalam melaksanakan hukuman dalam kasus jinayah, dengan maksud apa-apa yang ada dibawah Mahkamah Syariah adalah yang telah ditetapkan perlembagaan.

Wewenang Mahkamah Syariah menjatuhkan hukuman adalah tertakluk kepada peruntukan akta parlemen, yaitu Akta Mahkamah Syariah (Bidang kuasa Jinayah) 1965 (Pindaan 1984). Akta ini telah menyekat kebebasan dan kuasa negeri berkaitan dengan bidang kuasa jinayah Mahkamah Syariah. Akta ini memperuntukan Dewan Undangan Negeri hanya boleh mengubah kesalahan jinayah syariah yang hukumannya tidak melebihi 3 tahun penjara, denda lima ribu ringgit (RM 5000 bersamaan RP 13.500.000), dan enam kali cambuk. ${ }^{16}$ Dalam hal yang demikian Dewan Undangan Negeri tidak boleh mengubah hukuman yang lebih dari yang dinyatakan diatas. Akibatnya undangundang Islam sebetulnya tidak lagi menjadi undang-undang asas di Malaysia, dan tempatnya telah diambil alih oleh undang-undang Inggris.

Dari sudut sejarah, Mahkamah Syariah telah dipinggirkan semasa penjajahan Inggris. Mahkamah Syariah telah direndahkan kedudukannya sehingga menjadi mahkamah terbawah di dalam hierarki sistem keadilan semasa penjajahan Inggris, terutama setalah inggris memperkenalkan Courts Ordinance dalam tahun 1948. Sementara itu bidang kuasa Mahkamah Syariah telah dikikis dan keperluan prasarana telah diabaikan. Layanan ke atas Mahkamah Syariah adalah berbeda dengan Mahkamah sipil. ${ }^{17}$

\footnotetext{
${ }^{15}$ Abd Monir Haji Ya'kub, Perkembangan Perundangan Islam, 66.

16 Pasal 2 Akta No. 355 tentang Mahkamah Syariah (Bidang Kuasa Jenayah) 1965 yang diamendemen tahun 1984, h. 40

${ }^{17}$ Zainul Rijal Abu Bakar, Kertas Kerja Pelaksanaan Hukuman Sebat dalam Kes Jinayah Syariah: Cabaran dan Halangan.
} 
Mahkamah Syariah di Negeri-negeri telah ditubuhkan di bawah Enakmen Pentadbiran Agama Islam di Negeri-Negeri, selaras dengan Butiran 1 Senarai II Jadual Kesembilan Perlembangaan Persekutuan. Penubuhannya juga disertai dengan bidang kuasa eksklusifnya, yang melibatkan tuntutan ke atas kes-kes dan kasus jinayah setakat yang diperuntukan dalam perlembagaan persekutuan bagi orang-orang yang beragama Islam. ${ }^{18}$

Dalam melaksanakan bidang kuasa jinayahnya pula, Mahkamah Syariah pada peringkat awal, tidak diberi kuasa untuk menjatuhkan hukuman sebat (cambuk) terhadap mana-mana orang yang telah disabitkan atas sesuatu kesalahan jinayah syariah. Ini adalah karena berdasakan kepada Muslim Courts (Criminal Jurisdiction) Act 1965 [No. 23 of 1965], Mahkamah Syariah pada masa itu, di bawah bidang kuasa jinayahnya, hanya mempunyai bidang kuasa untuk mendengar dan memutuskan kes-kes jinayah yang melibatkan kesalahan-kesalahan yang boleh dihukum dengan penjara tidak melebihi enam bulan dan denda tidak melebihi seribu ringgit atau kedua-duanya.

Pada tahun 1986, suatu pindaan telah dibuat melalui Akta A612, yang memberi kuasa kepada Mahkamah Syariah untuk mendengar dan menjatuhkan hukuman terhadap kesalahan jinayah syariah yang boleh dihukum dengan penjara tidak melebihi tiga tahun denda tidak melebihi lima ribu ringgit atau hukuman sebat tidak melebihi enam kali sebatan atau kedua-duanya. Terkini, Akta tersebut telah dikenali sebagai Akta Mahkamah-Mahkamah Syariah (Bidang Kuasa Jinayah) 1965 [Akta 355] dan bidang kuasa yang melibatkan kesalahan-kesalahan yang dikenakan hukuman tersebut dikekalkan. ${ }^{19}$ Dengan bidang kuasa yang diberikan tersebut, hukuman sebat telah menjadi salah satu daripada hukuman terhadap beberapa kesalahan yang telah diperuntukan di bawah enakmen/ordinan/akta kesalah jinayah syariah di Negeri-Negeri dan Wilayah-Wilayah Persekutuan. ${ }^{20}$

\footnotetext{
18 Pelaksanaan Hukuman Sebat dalam kes Jinayah Syariah: Masalah dan penyelesaiannya Oleh Mahamad Naser Bin disa, Timbalan Ketua Bahagian Penyelidikan (Seksyen Syariah), Jabatan Peguam Negara dengan dan kawan-kawan. Dibentangkan dalam Seminar Hukuman Sebat Jinayah Syaraiah anjuran Jabatan Kemajuan Islam Malaysia (JAKIM) pada 23 April 2009.

19 Ibid.

${ }^{20} \mathrm{http} / / / \mathrm{ms}$.wikipedia.org/wiki/Mahkamah Syariah di Malaysia. di unduh pada 21 december 2010. 16.09 wib. Laman ini diubah buat kali terakhir pada 00:28, 4 Disember 2010.
} 
Sebagiamana yang diperuntukan oleh Perlembangaan Malaysia, kuasa Mahkamah Syariah adalah dibawah enakmen negeri. Tetapi tidak melebihi apa yang telah diperuntukkan, sebagaimana dalam Perlembagaan Malaysia 1965:

1. Kuasa Mahkamah Syariah yang telah diperuntukan oleh Perlembagaan Malaysia 1965 adalah seperti berikut:

a. Boleh membicara dan menghukum dengan hukuman penjara atau denda ke atas orang Islam sahaja

b. Denda tidak melebihi RM1000.00 sahaja atau

c. 6 bulan penjara atau

d. Gabungan kedua-duanya (denda dan penjara)

e. (Pindaan) Perlembagaan Malaysia 1984

Kuasa Mahkamah Syariah yang diperuntukan oleh Perlembagaan Malaysia 1984 dengan pindaan adalah seperti berikut:

2. Boleh membicara dan menghukum dengan hukuman penjara atau denda ke atas orang Islam saja

a. Denda tidak melebihi RM5000.00 sahaja atau

b. 3 tahun penjara atau

c. Hukuman rotan tidak melebihi daripada enam kali sebatan atau

d. Gabungan ketiga-tiganya (denda, penjara dan rotan)

3. Enakmen dan Akta Kekeluargaan Islam di Malaysia

Undang-undang kekeluargaan Islam merupakan suatu akta bagi mengkanun peruntukan-peruntukan tertentu undang-undang kekeluargaan Islam mengenai perkawinan, penceraian, nafkah, penjagaan dan lain-lain yang berkaitan dengan kehidupan keluarga. Setiap individu di Malaysia boleh merujuk kepada undang-undang kekeluargaan mengikut negeri masing-masing. ${ }^{21}$

\section{Kategori Hukuman Pelaku Pezina di Mahkamah Syariah Sarawak Malaysia}

Sebelum Akta Parlimen 1965 Mahkamah Syariah (Bidang Kuasa Jenayah) pindaan 1984, Mahkamah Syariah seluruh Malaysia tidak mempunyai bidang kuasa untuk mengenakan hukuman bagi pelaku penzina terhadap pesalah-pesalah jinayah syariah dan apabila Akta tersebut dipinda mengikut pindaan Akta A612 dan digazet kuat

\footnotetext{
21 Forum Feqh Perundangan dan Pengertian Jinayah. Diunduh pada 21 December 2010. http://halaqah.net/v10/index.php?topic=7538.10;wap2.
} 
kuasanya pada 1.1.1986 barulah Mahkamah Syariah seluruh Malaysia mempunyai bidang kuasa yang lebih sedikit berbanding sebelumnya iaitu diberi kuasa tiga tahun penjara, denda RM5000.00 (Rp 13500000) mengikut perkiraan sekarang dan 61 sebatan atau mana-mana kombinasi daripada hukuman tersebut. Jelas mahkamah syariah telah ditentukan wewenangnya, tanpa diberi kebebasan sendiri.

Di Malaysia, hukuman zina yang dikenakan sebagai suatu hukuman bagi kesalahan jinayah dalam tiga kategori seperti yang berikut: a. Hukuman zina bagi kesalahan jinayah yang dijatuhkan oleh mahkamah sivil seperti kesalahan merogol di bawah seksyen 376 Kanun Keseksaan [Akta 574], kesalahan mengedar dadah di bawah seksyen 39A Akta Dadah Berbahaya 1952 [Akta 234] dan kesalahan memiliki senjata api secara haram di bawah seksyen 8 Akta Senjata Api (Penalti Lebih Berat) 1971 [Akta 37].

b. Hukuman zina yang diawardkan oleh Pegawai yang Menjaga di bawah Peraturan-Peraturan Penjara 2000 [P.U. (A) 325/2000] (Peraturan Penjara) karena kesalahan yang dilakukan oleh seorang banduan di dalam penjara seperti melarikan diri atau cuba melarikan diri di bawah subperaturan 123(b) Peraturan Penjara; dan

c. Hukuman zina bagi kesalahan jinayah yang dijatuhkan oleh mahkamah Syariah yaitu di bawah enakmen/ordinan/akta kesalahan

Pelaksanaan setiap hukuman zina yang dijatuhkan bagi setiap kategori tersebut hanya diberi kuasa kepada pihak penjara. Selain iu terdapat prosedur khusus yang telah diperuntukkan oleh undang-undang dalam melaksanakan hukuman zina yang telah dijatuhkan bagi kategori tersebut, prosedur-prosedur tersebut terkandung dalam undang-undang berikut:

1. Kanun Acara Jenayah [Akta 593] (KAJ);

2. Peraturan Penjara

3. Enakmen/ordinan/akta tatacara jenayah Syariah di bawah model undang-undang seragam yang telah diluluskan oleh Majlis Raja-Raja dan telah dikuatkuasakan di kebanyakan Negeri dan Wilayah Persekutuan. ${ }^{22}$

Berdasakan peruntukan-peruntukan yang dinyatakan di atas pelaksanaan hukuman zina oleh pihak penjara hendaklah mematuhi

22 Ordinan Tatacara Jenayah Syariah (Negeri Sarawak) 2001 [Ordinan 46/2001] (Ordinan Tatacara Jenayah Syariah Sarawak) 
prosedur-prosedur yang telah di tetapkan mengikut mahkamah yang menjatuhkan hukuman zina tersebut, dengan kata lain sekiranya sesuatu hukuman zina itu dijatuhkan oleh mahkamah sipil bagi kesalahan jinayah yang berada di bawah bidang kuasa mahkamah sipil, maka KAJ (Kanun Acara Jinayah) dirujuk bagi melaksanakan hukuman zina tersebut.

Manakala sekiranya hukuman zina itu bagi kesalahan yang dilakukan oleh banduan ketika berada di bawah penjagaan penjara, maka prosedur bagi pelaksanaan hukuman zina yang terpakai adalah sebagaiamana yang terkandung dalam Peraturan Penjara, begitu juga bagi kesalahan jinayah syariah yang dijatuhkan hukuman zina oleh mahkamah syariah, prosedur yang terpakai bagi melaksanakan hukuman tersebut adalah sebagaimana yang terkandung dalam enakmen/ordinan/akta, melihat pada enakmen atau ordinan bagi kesalahan yang dikenakan hukuman cambuk di mahkamah syariah jika diteliti pemberlakuannya tidak dilaksanakan.

\section{Jinayah Syariah yang Membawa Hukuman Zina}

Menurut ordinan kesalahan jinayah syariah negeri-negeri, kesalahan jinayah syariah yang boleh dikenakan cambuk ialah kesalahankesalahan seksual seperti mengadakan persetubuhan luar nikah atau zina, muqaddimah zina atau perbuatan sebagai persediaan untuk melakukan persetubuhan luar nikah, perbuatan sumbang mahram atau perhubungan muabbad dang hair muabbad, pelacuran, melacurkan isteri atau anak, muncikari, dan persetubuhan bertentangan dengan hukum tabii (liwât dan musâhaqah). Selain itu, kesalahan meminum minuman yang memabukkan dan menyebarkan dotrin palsu juga adalah antara kesalahan lain yang boleh dikenakan hukuman cambuk.

Selain daripada peruntukan hukuman zina terhadap pelbagai kesalahan yang diterangkan di atas, Akta 1 Enakmen Tatacara Jinayah Syariah di negeri-negeri tersebut yaitu Wilayah Persekutuan, Pahang, Selangor, Perak dan Sabah menyediakan peruntukan tentang kaedah dan cara bagaimana hukuman zina itu hendak dijalankan, namun begitu, sehingga kini, belum ada satu negeri pun yang melaksankannya. ${ }^{23}$

\footnotetext{
${ }^{23} \mathrm{http}: / /$ ppsml.blogspot.com/2010 0214 archive.html, laman rasmi PPSM. Ahli PPSM terdiri dari pegawai-pegawai kerajaan dalam skim perkhidmatan Pegawai Syariah yang berkhidmat sebagai Pegawai di JKSM, Hakim Syari'e, Pendaftar, Ketua Pendaftar, Pegawai Penyelidik, Pegawai Sulh dan
} 
Kesalahan-kesalahan jinayah syariah yang membawa kepada hukuman zina adalah berbeza antara satu negeri dengan negeri yang lain. Setelah mencapai kemerdekaan hampir 53 tahun, tetapi masalah penyeragaman undang-undang dan adanya beberapa perbezaan peruntukan yang terkandung di dalam ordinan-ordinan atau akta undang-undang jinayah Syariah negeri-negeri di Malaysia masih berlaku, ini adalah disebabkan banyak negeri yang tidak memakai undangundang kesalahan jinayah syariah.

Isu penyelarasan undang-undang syariah bagi negeri seluruh Malaysia bukannya satu perkara baru dan banyak usaha telah dilaksanakan untuk menyeragamkan undang-undang syariah, namun sehingga kini ia masih belum dapat mencapai matlamatnya, namun sebagaimana dinyatakan terdahulu walau apapun kesalahan yang boleh membawa hukuman cambukan, hukuman cambuk maksimum yang boleh dikenakan adalah tidak melebihi enam kali sebatan.

Ketidakseragaman dari aspek hukuman yang dikenakan, sebagai contoh di dalam kasus melibatkan kesalahan perzinahan atau kesalahan yang berhubungan dengan kesusilan, seksyen 17 Ordinan kesalahan jinayah syariah (Sarawak) 2001 memperuntukan hukuman denda tidak melebihi lima ribu ringgit atau penjara tidak melebihi tiga tahun atau kedua-duanya, manakala seksyen 7 Akta Jinayah Syariah (Wilayah Persekutuan) 1997 menyatakan hukuman denda yang sama tetapi penjara hanya tidak melebihi dua tahun atau kedua-duanya. ${ }^{24}$

Menunjukan adanya ketidaksamaan undang-undang dari setiap negeri terjadi, padahal adalah lebih baik undang-undang itu dibuat berseragam, umat Islam tidak akan ragu-ragu, karena pasti ada timbul kekeliruan apakah negeri ini menjalankan hukum Islam padahal melihat pada negeri lain tidak menjalankannya.

\section{Simpulan}

Hukuman zina yang ditetapkan Allah ini bukan untuk menyusahkan manusia tetapi banyak efek jeranya yang akan membuatkan diri manusia lebih menghormati manusia lain. Di

\footnotetext{
Pegawai Bahagian Sokongan Keluarga (BSK) di undang (Syariah) negeri-negeri, Pendakwa Syari'e negeri-negeri dan Peguam di Jabatan Biro Bantuan Guaman.

${ }^{24}$ Enakmen Jinayah Syariah (Selangor) 1995
} 
dalamnya terdapat hikmah dan rahmat Allah. Dan dengan cabaran umat sekarang ini maka patutlah kita kembali kepada Al-Qur'an dan Hadis.

Polemik yang berlaku dalam kasus hukuman zina dipandang kejam adalah karena kurangnya pemahaman malah penghayatan disebalik hukuman itu, malah terjadi dikalangan muslim sendiri, jika ini berlaku di kalangan non-muslim akan lebih merasa bahawa hukum Islam itu keras, dan menjadi peranan bagi kerajaan, malah media yang sedang berkembang luas untuk menyebar dan menyampaikan kepahaman yang sebenar.

Perlu diberikan kewenangan kepada Parlimen bagi propinsi maupun DUN yang mewakili propinsi agar dapat bersama dalam menetapkan undang-undang, dan seharusnya tidak mengenyampingkan syariat. Pentingnya ada permersatuan ulama' dan para cendikiawan dalam mengenalkan masyarakat tentang hukum Islam yang sebenarnya.

Mahkamah Syariah maupun lembaga yang menjalankan hukum Islam haruslah mempunyai wewenang yang penuh dalam menjalankan hukum agama dan mendukung kerajaan dengan menyebar dan menerangkan arti sebenar hukum Islam yang ingin diberlakukan.

\section{Daftar Rujukan}

Abdullah, Abdul Rahan. Pemikiran Islam di Malaysia. Jakarta: Gema Insani Press, Cet. 1, 1997.

Bakar, Zainul Rijal Abu. Kertas Kerja Pelaksanaan Hukuman Sebat dalam Kes Jinayah Syariah: Cabaran dan Halangan.

Naim (an-), Abdullah Ahmed. Dekonstruksi Syariah; Wacana Kebebasan Sipil, Hak Asasi Manusia dan Hubungan Internasional Dalam Islam. Yogyakarta: LKIS, Cet ke 4, 2004.

Nisaburi (an-), Al-Imam Abi Husain Muslim Bin Hajjaj Al_Qusairi. Shahih Muslim. Beirut: Darul Kutub al-Ilmiah, t.th.

Djazuli, A. Hukum Pidana Islam (Fiqh Jinayah). Jakarta: CV Pustaka Setia, Cet. 2, 2010.

http://halaqah.net/v10/index.php?topic=7538.10;wap2.

http://ms.wikipedia.org/wiki/Mahkamah Syariah di Malaysia di unduh pada 21 december 2010.

http://ppsml.blogspot.com/2010 0214 archive.html 
Ibrahim, Ahmad Mohammed. Pentadbiran Undang-Undang di Malaysia. t.th.

Ishak, Abdullah. Islam di Nusantara Khususnya di Tanah Melayu. Malaysia: Hal Ehwal Islam Jabatan Perdana Menteri, Cet. 2, 1992.

Malik, Muhammad Abduh. Prilaku Zina Perundangan Hukum Islam dan KUHP

Muhammad, Daud B. Haji. Ketua Penyelia Agama, Kelantan. Kelantan: Jabatan Hal Ehwal Ugama Islam, t.th.

Nasohah, Zaini. Pentadbiran Undang-Undang Islam di Malaysia Sebelum dan Menjelang Merdeka. Malaysia: Percetakan Cergas (M) Sdn Bhd, Cet. I, 2004.

Pelaksanaan Hukuman Sebat dalam kes Jinayah Syariah: Masalah dan penyelesaiannya Oleh Mahamad Naser Bin disa, Timbalan Ketua Bahagian Penyelidikan (Seksyen Syariah), Jabatan Peguam Negara dengan dan kawan-kawan, dibentangkan dalam Seminar Hukuman Sebat Jinayah Syaraiah anjuran Jabatan Kemajuan Islam Malaysia (JAKIM) pada 23 April 2009.

Ya'kub, Abd Monir Haji. Perkembangan Perundangan Islam. Malaysia: Penerbitan Sarjana (M) Sdn Bhd, Cet. 1, 1985.

Yahya, Mahyudin Haji. Islam dan Pembangunan Negara. Malaysia: University Kebangsaan Malaysia, Cet. I, 1986.

Zuhaili, Wahbah. Fikih Imam Syafi'i. Al-Mahira, Cet. 1, 2010.

Yayasan Penyelenggara Penterjemah/Pentafsir al-Qur'an, Al-Qur'ân alKarîm wa Tarjamah Ma'ânîhi Ila Al-Lughah al-Indûnîsiyyah. 